\title{
UKÁZKY TÝMOVÝCH PŘEKLADŮ OD ÚČASTNÍKŮ WORKSHOPU HLEDÁME JÁDRO PUDLA ${ }^{1}$
}

\section{Christian Morgenstern: Gruselett}

Der Flügelflagel gaustert durchs Wiruwaruwolz, die rote Fingur plaustert, und grausig gutzt der Golz.

\section{I}

\section{Strašinet}

Křídelskřípel strášní vychrastěným chlestím, fingura ježirúdní, dasí se dušením.

(překlad Lukáš Felbr, Anna Fišerová, Jelizaveta Getta)

II

(úryvek)

Kouklík rousný v chroštivu úpí nezná neklidu.

(...)

(překlad Tereza Matoušová a kol.)

III

Hrůzinec

Hejnují se letopýři, strašitají v hřivohřoví, fingura se černopýř́i, sovýc vrhá kukuč hřivý.

(překlad Daniela Čechová, Veronika Francová, Lenka Zbořilová)

1 Překladatelských workshopů pod vedením Pavla Novotného a Radka Malého se účastnili (v abecedním pořadí): Andrea Čapková, Daniela Čechová, Lukáš Felbr, Veronika Francová, Marie-Louise Gatzke, Jelizaveta Getta, Agnes Hain, Karolína Havlínová, Katrin Hoffmanová, Mirjam Kreisel, Barbora Krejčová, Kristina Kučerová, Anežka Matěnová, Tereza Matoušová, Tomáš Michálek, Julia Miesenböck, Alexandra Morozová, Charlota Moudra, Alena Paulik, Margarete Rössler, Lucie Rudolecká, Matti Simon, Jan Sládek, Mathilde Stangenberger, Lucie Titscher, Lenka Zbořilová, Ylias Zivana. 
IV

\section{Strašikré}

Krákulous kejsek prritrh

co lesolesím laz,

kde rudý fingúr škabrt,

a straše skostř́í sd’as.

(překlad Kateřina Návarová)

\section{Joachim Ringelnatz: Die Ameisen}

In Hamburg lebten zwei Ameisen,

Die wollten nach Australien reisen.

Bei Altona auf der Chaussee

Da taten ihnen die Beine weh,

Und da verzichteten sie weise

Dann auf den letzten Teil der Reise.

I

Mravenci

V Praze žili dva mravenci, chtěli do Austrálie utéci.

Na Čerňáku u dálnice

nohy necítili více,

tak to na půl cesty vzdali

a na zbytek se vykašlali.

(překlad Lukáš Felbr, Anna Fišerová, Jelizaveta Getta)

II

Mravenečci

Dva malincí mravenečci

chtěli z Prahy na Bali.

A pak v metru na Florenci

nohama po nich dupali.

Tu si oba svorně řekli -

že jsme se na to nevypekli.

(překlad Tereza Matoušová a kol.)

III

Mravenci (verze I pro děti ze všech částí Česka)

Žili byli dva mravenci z Prahy, co chtěli v létě vidět moře, 
však už tuze bolely je nohy,

sotva došli k první hoře,

a tak se moudře rozhodli,

že dají přednost pohodlí.

(překlad Daniela Čechová, Veronika Francová, Lenka Zbořilová)

IV

Mravenci (verze II pro děti ze všech částí Česka)

Žili byli mravenečci z Olomouce, co vydali se do Ameriky po louce, ale nožičky rozbolely je právě, když ocitli se u dolu v Ostravě, a tak moudře „Zpátky!“ zaveleli a zbytek cesty radši oželeli.

(překlad Daniela Čechová, Veronika Francová, Lenka Zbořilová)

\section{H. C. Artmann: tom du tümmel}

tom

tom tom tümmel

tom du tom und tom

o tom du

lederne cappen

tom du

tom tom

du tom tom

am himmel tom

dreh tom dreh dreh

deine cappen tom

tom du tümmel

dreh du

canonen tümmel

tom du

tom

I

tom tentam

tam

tam tytrosko

tam ty tam no tam

no tam ty

kápo koženej

tam ty

tam tam 


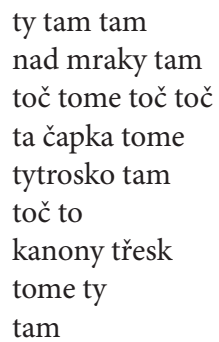


toč ty

kanony tlačí

tam ty

tam

(překlad Alena Paulik)

IV

BEN

BEN BEN BLBÉ

BENE BENE BEN

NÉ BENE

KOŽENÝ KUKLY

BENE

BEN BEN

BENE, NA NEBI!

BER JE BEN BER

TVÝ KUKLY BEN

BENE BLBE

BER JE

KANÓNY BLBĚ

BENE

BEN

(překlad Kateřina Návarová)

V

tam tome

tam

tam tam tome

tam ty tam a tam

a tam ty

kožené čapky

tam ty

tam tam

ty tam tam

nad tebou tam

ted' tam ted' ted'

další čapky tam

ty tam tome

ted' ty

kanóny tome

tam ty

tam

(překlad Daniela Čechová, Veronika Francová, Lenka Zbořilová) 


\section{H. C. Artmann: Die Fahrt zur Insel Nantucket}

$\begin{array}{ll}\text { die see wie ein } & \text { grüner atlas in unruhe: } \\ \text { freweguest: } & \begin{array}{l}\text { der schiffe hochstier drühmt } \\ \text { und raat } \\ \text { zu hellezont im sand verlohr.. }\end{array} \\ \text { rutherfurt: } & \begin{array}{l}\text { einschwärmt mit losem lischer } \\ \text { scheere fisch auf fisch.. } \\ \text { die ballen staulos } \\ \text { coninxtrum: }\end{array} \\ & \begin{array}{l}\text { starm und staut gehen auf und ab } \\ \text { und lee und lie mestaal.. } \\ \text { bagien und besam traulop } \\ \text { kühl belakt und grau vor hallborn }\end{array} \\ & \text { voll lvor nebelluuv.. }\end{array}$

\section{Úryvek z divadelní hry Die Fahrt zur Insel Nantucket}

moře jako zelený atlas tonoucí v neklidu:

žeňgost: těch lodí sněžejň zasnívá

a pakrak

soublačným pískem ztrácí se..

feslbrod: tu ohejněna žralály

ryba rybu zdíhá..

pankrol: $\quad$ a v závalu rejdí rybošum

šupí nahodorů

$\mathrm{v}$ návětrný bok

žeňgost: belga a daskar chladověrné

$\mathrm{v}$ šedokrytu tramburském

zamlhený zduch..

(překlad Tereza Matoušová a kol.)

\section{Georg Trakl: An den Knaben Elis}

Elis, wenn die Amsel im schwarzen Wald ruft,

Dieses ist dein Untergang.

Deine Lippen trinken die Kühle des blauen Felsenquells.

Laß, wenn deine Stirne leise blutet

Uralte Legenden

Und dunkle Deutung des Vogelflugs.

(...) 
Elisovi

Elisi, až kos v černém lese zakřičí,

Vše bude ztraceno.

Na rtech ucítíš chlad modrého pramene ze skály.

Zanech, až ti z čela tiše poteče krev

Prastarých legend

A temného proroctví ptačích křídel.

(překlad Lukáš Felbr, Anna Fišerová, Jelizaveta Getta)

II

Chlapci jménem Elis

Elisi, pěje-li v černém lese kos, tvou to zkázu znamená.

Tvoje ústa pijí chlad z modrého pramene skal.

(...)

(překlad Tereza Matoušová a kol.)

III

\section{Chlapci Elisovi}

Elisi, když volá kos v černém lese,

To jest tvým zánikem.

Tvé rty pijí chlad modrého pramene skal.

Zanech, když čelo ti tiše krvácí

Prastaré legendy

A temný výklad ptačího letu.

(překlad Kateřina Návarová)

\section{Rainer Maria Rilke: Herbsttag}

Herr: es ist Zeit. Der Sommer war sehr groß. Leg deinen Schatten auf die Sonnenuhren, und auf den Fluren laß die Winde los.

Befiehl den letzten Früchten voll zu sein; gieb ihnen noch zwei südlichere Tage, dränge sie zur Vollendung hin und jage die letzte Süße in den schweren Wein.

Wer jetzt kein Haus hat, baut sich keines mehr. Wer jetzt allein ist, wird es lange bleiben, 
wird wachen, lesen, lange Briefe schreiben und wird in den Alleen hin und her unruhig wandern, wenn die Blätter treiben.

\section{Podzimní den}

Pane: je čas. Léto bylo velké.

Ulož svůj stín na sluneční hodiny, nech skrz doliny plát vánky lehké.

Přikaž posledním plodům zrát plně; dej zasvítit na ně dvou jižnějších dní, jen at jsou dokonalé a dopadni zbytky sladkosti v tvém těžkém víně.

Kdo nemá dům, už jej nepostaví.

Kdo je dnes sám, jen tak nebude s druhým, jen bdít, číst, věnovat se písmům dlouhým, vstupovat na zmatené výpravy, sem tam álejí, nesen listím pouhým.

(překlad Kateřina Návarová)

\section{Gottfried Stix}

helleres rausche im frischen bergwind wehen die blüten zum bach

jasnější šelest horská svěží povětří květy koukol dmou (překlad Kateřina Návarová) 
Originály překládaných literárních děl pocházejí z těchto publikací:

Artmann, Hans Carl: Die Fahrt Zur Insel Nantucket: Theater, München: Hermann Luchterhand Verlag 1969.

Artmann, Hans Carl: Sämtliche Gedichte. Salzburg/Wien: Jung und Jung 2003.

Morgenstern, Margareta (ed.): Christian Morgenstern. Gesammelte Werke in einem Band. München: R. Piper 1965.

Rilke, Rainer Maria: Sämtliche Werke. Band 1-6, Band 1, Wiesbaden/Frankfurt a.M.: Insel Verlag 1955-1966.

Ringelnatz, Joachim: Hell und schnell. 555 komische Gedichte aus 5 Jahrhunderten. Frankfurt: Fischer-Verlag 2004.

Stix, Gottfried W. et al: Podium-Porträt. Ausgewählte Gedichte. München: Deutscher Taschenbuch Verlag 2001.

Trakl, Georg: Das dichterische Werk. München: Deutscher Taschenbuch Verlag 1998. 